\title{
Confinement Behavior of Spun Pile using Low Amount of Spiral Reinforcement - an Experimental Study
}

\author{
Candra Irawan ${ }^{1 *}$, Rudy Djamaluddin ${ }^{\#}$, I Gusti Putu Raka ${ }^{2 *}$, Faimun $^{3 *}$, Priyo Suprobo ${ }^{4 *}$, Gambiro $^{+}$ \\ *Department of Civil Engineering, Institut Teknologi Sepuluh Nopember, Surabaya, 60111, Indonesia \\ ${ }^{1}$ E-mail: candra.irawan.its@gmail.com, ${ }^{2}$ raka@ce.its.ac.id, ${ }^{3}$ faimunf@gmail.com, ${ }^{4}$ priyo@ce.its.ac.id \\ "Department of Civil Engineering, Hasanuddin University, Gowa 92171, Indonesia \\ E-mail:rudy0011@gmail.com
}

${ }^{+}$PT Wijaya Karya Beton, Tbk., Jakarta, Indonesia

E-mail: gambiro.s@wika-beton.co.id

\begin{abstract}
In this paper, further analysis from the result of spun pile test under reverse flexural load and combined with two levels constant axial load, 40 tons $\left(0.08 f c^{\prime} \mathrm{Ag}\right)$ and 80 tons $\left(0.16 \mathrm{fc}^{\prime} \mathrm{Ag}\right)$ is presented. The analysis is related to the confinement behavior of the concrete section of pile using the low amount of spiral reinforcement. It was shown that the strain readings from the spiral reinforcement indicate a subtle contribution regarding the confinement mechanism of the hollow section of a pile. In addition, it was evident that spiral reinforcement seems to be compressed when the concrete section resists compression strain due to flexural load. The crushing of concrete at ultimate condition could also not be resisted by spiral reinforcement by any means.
\end{abstract}

Keywords - Confinement behavior, spun pile, low amount of spiral reinforcement.

\section{INTRODUCTION}

In high seismic risk utilization, the requirement of piles is strictly specific by design specifications. In the level of design, this requirement involves the minimum ductility, ratio, and diameter of transverse reinforcement to ensure the piles have adequate strength to support the weight of upper structure is subjected to significant earthquake loading.

The role of the spiral reinforcement as confinement is anticipated to obtain ductile performance on a prestressed pile. The role is subject to alleviate the plastic hinge mechanism thereby allowing the structure to behave as a nonlinear member. This can be done by utilizing closelyspaced transverse reinforcing bars to confine the compression zone of a pile [1]. As a result, high ductility can be obtained with the value not less than 8 [2-4].

A prestressed hollow pile, otherwise termed as the spun pile, generally demands sufficient ductility when behaves as a free-standing column which mostly relies on the use pile shaft with the soil confinement being neglected. Irawan et al. [5] investigated the seismic performance of hollow prestressed concrete pile subjected to reversed flexural load combined with two levels of constant axial load. The result showed that the displacement ductility of specimens which axially loaded with 40 tons $\left(0.08 f_{c}^{\prime} A_{g}\right)$ and 80 tons $\left(0.16 f_{c}^{\prime} A_{g}\right)$ were 4.8 and 2.4 , respectively. By design specifications [6$7]$, the results indicate that either specimen exhibits low ductility; therefore, a flexible design is prohibited, test specimens can only be used in a low and high seismic risk area with remain elastic condition. Prior research with similar interest was also carried out by Budek and Priestly [8]. The results showed that under lateral load the prestressed hollow piles collapsed at displacement ductility around 4.

In this paper, further analysis about the experimental investigation conducted by Irawan et al. [5] is presented. The analysis is based on experimental work which is related to the confinement behavior of spun pile under flexural load. The study is directed toward to understanding how the low ratio of spiral reinforcing bars $\left(\rho_{t}=0.0024\right)$ could, therefore, affect the performance of spun pile. Accordingly, this present study also adopts an advanced analysis to assess the seismic performance of spun pile. Failure mechanism at the end of loading phase is also studied as well as visual 
observation through the readings from strain gauges mounted on the concrete, and longitudinal and transverse reinforcement. These readings can be used to justify the level confinement provided by the concrete and reinforcements. The previous research regarded to seismic performance of hollow pile are presented below.

Three groups of hollow piles with a diameter of $400 \mathrm{~mm}$ and a wall thickness of $70 \mathrm{~mm}$, built with high strength concrete (ave. 87.4 MPa) [9]. The specimens were varied the ratio of transverse reinforcement and added non-prestressed longitudinal steel. Specimens were laterally loaded at midspan in merely supported, with a span $2.6 \mathrm{~m}$. This investigation concluded that adequate close spacing of transverse reinforcement would provide confinement to the core, and produce a ductile performance of hollow pile. The additional non-prestressed longitudinal reinforcement would also produce a ductile response, even after the failure of the prestressed longitudinal steel.

High-strength spun concrete hollow prestressed piles were laterally loaded at midspan in merely supported, with a span $5 \mathrm{~m}$ [10]. The diameter was $400 \mathrm{~mm}$ with a wall thickness $150 \mathrm{~mm}$. The strength of concrete was 95-106 MPa. The ratio of transverse reinforcement with yield strength 1,000 $\mathrm{MPa}$ was used. The maximum uniform elongation of the prestressing bars was evaluated in this study; bars with $2 \%$ $5.13 \%$ were used. The conclusions of this research were the flexural ductility of the spun pile was proportional to elongation of longitudinal steel. Adequate confinement of compression concrete fiber using sufficient the amount and spacing of transverse reinforcement would lead to the undesirable failure mode of the spun pile if the tensile capacity of the longitudinal bars was exceeded.

The monotonic and cyclic lateral loading was carried out in the spun piles, without axial load[11]. Specimens had 30 $\mathrm{cm}$ diameter and $6 \mathrm{~cm}$ thickness. The compressive strength of the concrete was fc' $=69 \mathrm{MPa}$. Six prestressed steel bars (PC bars) of $7 \mathrm{~mm}$ diameter were used for longitudinal reinforcement and spiral of $3 \mathrm{~mm}$ diameter and $100 \mathrm{~mm}$ pitch were used for transverse reinforcement. Piles were embedded into the soil. The locations of plastic hinge were the focus of this research. For monotonic loading, the plastic hinge was formed at a depth twice the diameter of the pile (2D). While plastic hinge was visible on the fourth diameter of the pile (4D) for cyclic loading.

Four test units, designated PS11-PS14, were hollow prestressed pile with a diameter $610 \mathrm{~mm}$ and a wall thickness $94 \mathrm{~mm}$ [8]. The strength of concrete was ave. 67.5 MPa for PS11-PS 13 and 53.5 MPa for PS14. Reversed lateral load combining with axial load applied to the pile. External confinement of pile section applied to PS 11 and PS13 by the saddles made from a 75 Duro "A" rubber that covered $100^{\circ}$ of pile shaft circumference top and bottom. The conclusions drawn from this test were the failure initiated due to compression failure of the shell when the strain at the core's inner surface reached a value about 0.005 . The presence of non-prestressed longitudinal bars caused the decreasing of curvature capacity by damaging the shell trough bond slip, initiating compression failure. External confinement by the saddle and the level of transverse reinforcement ratio on the plastic hinge region has no effect on displacement ductility capacity.
The experimental investigation described herein differs from previous research, in that the spun piles were tested under axial load and reversed lateral two points load. The previous work tested under monotonic lateral load without axial load [9-11]. The utilization of piles was not only embedded in the ground but also used as freestanding columns such as in marine and bridge structure. In case fixed head structure, high bending moment will occur on pile shaft under pile head as shown in

Fig. 1 [12]. Therefore, the pile was freely deflected without resisted by soil resistance. This research investigated the flexural behavior of spun pile combining with a constant axial load.

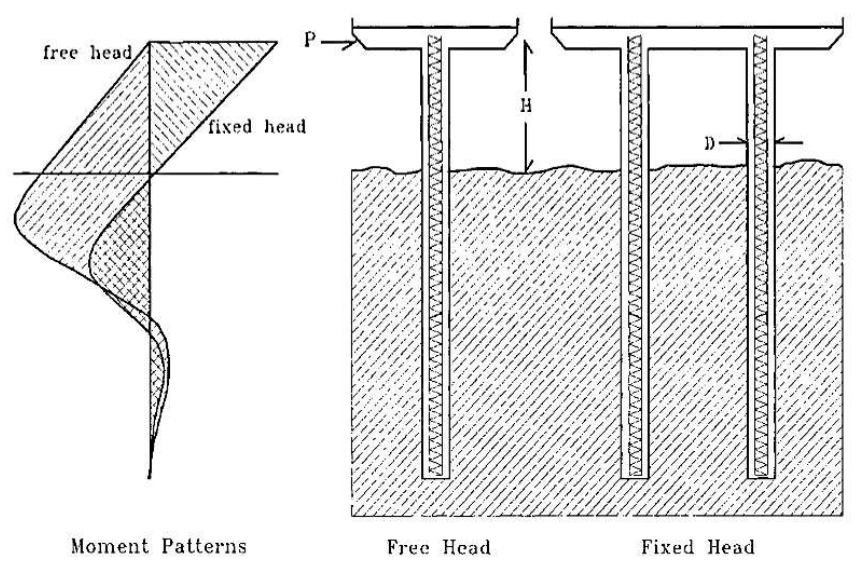

Fig. 1 Moment patterns in free and fixed-head piles [12]

\section{MATERIAL AND METHOD}

\section{A. Specimens}

This study involved two test specimens of spun piles, designated as S-TB-1 and S-TB-3. The specimens were tested under the similar environment, with the difference of the axial load being applied to each of test specimens as the parameter. Specimen S-TB-1 was axially loaded with 40 tons $(0.08 \mathrm{fc}$ 'Ag) while S-TB-3 was loaded with the axial load of 80 tons ( $\left.0.16 \mathrm{fc}^{\prime} \mathrm{Ag}\right)$.

The test specimens had a circular hollow section with diameter was $400 \mathrm{~mm}$ and a wall thickness of $100 \mathrm{~mm}$. The ratio of thickness and outer diameter, $\mathrm{t} / \mathrm{d}$, was 0.25 . Specimens were fabricated using the spinning method. Hollow section of concrete was produced due to centrifugal force were placed on the outer face of molding. A single layer of reinforcement consisted of ten prestressed PC bars with a diameter $7.1 \mathrm{~mm}$ were embedded to pile as longitudinal reinforcement. In addition, transverse reinforcement used $\varnothing 3.2 \mathrm{~mm}$ wire with $100 \mathrm{~mm}$ spacing. Pile's section and detail of reinforcement are shown in Fig. 2.

\section{B. Property of Materials}

The concrete had a compressive strength of fc' $54.4 \mathrm{Mpa}$ obtained at 28-day-age testing. Due to initial prestressing, the initial compressive stress was $\mathrm{f}_{\mathrm{c} 0} 4.6 \mathrm{Mpa}$. 


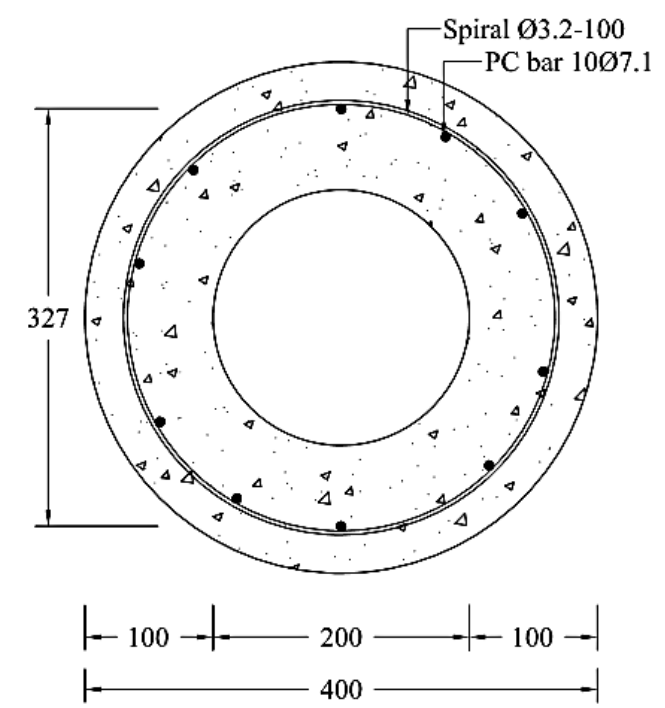

Fig. 2 Cross section and reinforcement's details

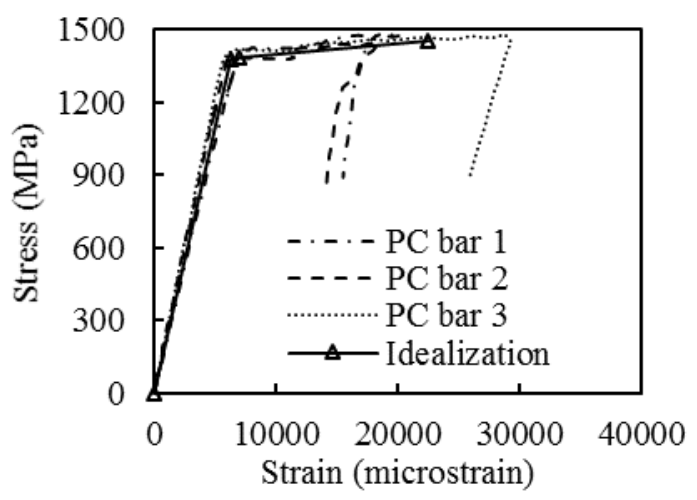

Fig. 3 The curve of stress-strain of PC bar $\varnothing 7.1 \mathrm{~mm}$ under tensile load

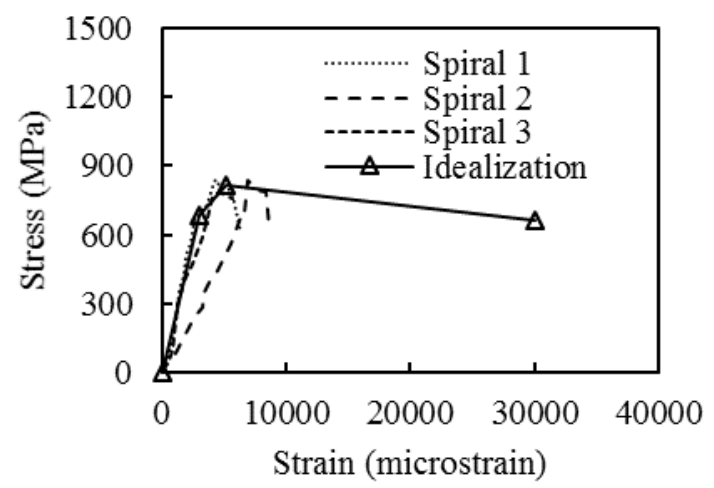

Fig. 4 The curve of stress-strain of spiral reinforcement, wire $\varnothing 3.2 \mathrm{~mm}$, under tensile load

Tensile properties of $7.1 \mathrm{~mm}$ PC bar are shown in Fig. 3 . Given its diameter, the PC bar had the area of $39.6 \mathrm{~mm}^{2}$. The elastic modulus of the bar was 220,267 Mpa, while the yield and ultimate stresses were 1,387 $\mathrm{Mpa}$ and 1,455 Mpa, respectively. While the yield and ultimate strain are $6,998 \mu \varepsilon$ and $22,529 \mu \varepsilon$ respectively. Regarding strain, due to initial prestressing, PC bars were subjected to 5,000 $\mu \varepsilon$ tensile strain.

Tensile properties of wire spiral reinforcement are shown in Fig. 4. The cross-sectional area was $8.0 \mathrm{~mm}^{2}$. Modulus of elasticity obtained from the linear gradient of the graph was 220,200 Mpa, while the yield and ultimate stresses and strain in respective were $681 \mathrm{Mpa}$ and $818 \mathrm{Mpa}$, and 3,067 $\mu \varepsilon$ and $5,219 \mu \varepsilon$.

\section{Setup and Loading System}

The test setup of specimens is presented in Fig. 5. Both specimens were tested under reversed flexural loading combined with constant axial load, 40 tons for S-TB-1 and 80 tons for S-TB-3. These loads represent the gravity and seismic load.

The specimens were tested as merely supporting structure, with pin-pin support at both ends, in a vertical position. A constant axial load was applied using 300 tons oil jack mounted on the top section of the spun pile. The pressure force was generated by the oil pump and controlled using a pressure gauge. Upside pin support was designed to can movable vertically to transmit the axial load from jack to pile section while reverse flexure load applied in the middle span of spun pile using 150 tons actuator.

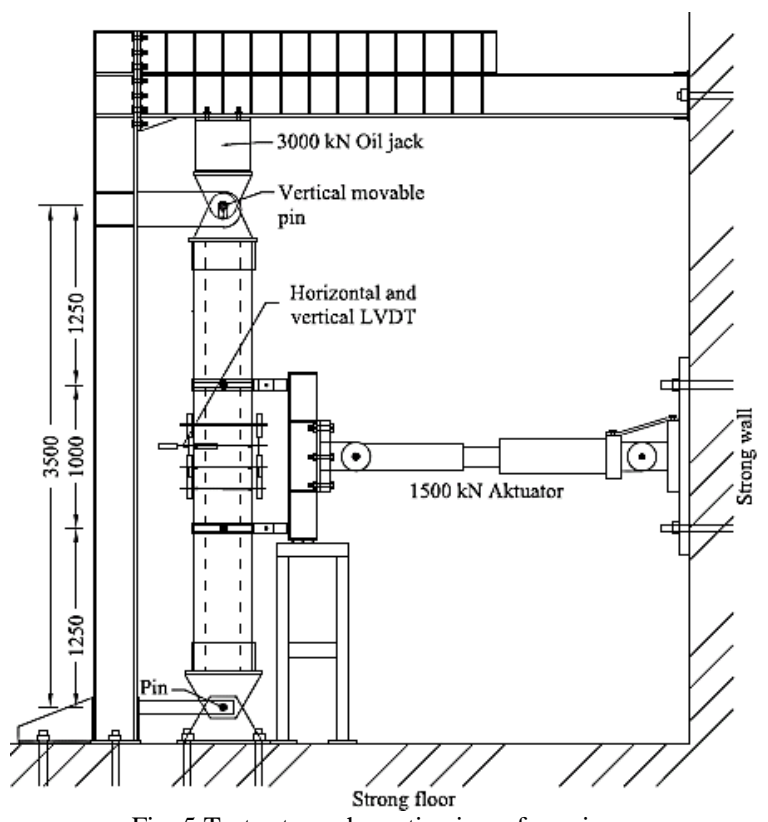

Fig. 5 Test setup schematic view of specimens

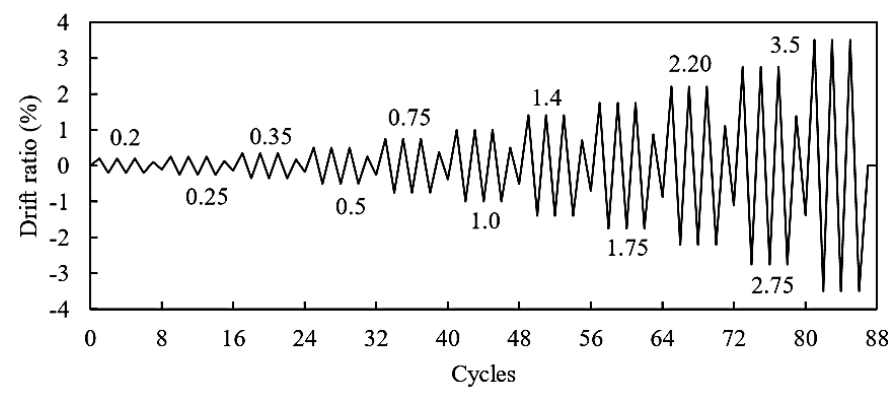

Fig. 6 The drift ratio of the loading protocol [13]

The lateral load was controlled by lateral displacement, recorded using $100 \mathrm{~mm}$ Linear Variable Differential Transducer (LVDT) instrument. Based on the displacement was obtained the value of drift ratio, a ratio between lateral displacement and shear span $(\mathrm{h} / 2)$, at the middle length of the specimens. The loading protocol was based on ACI 3741-05. The constant reverse displacement was repeated three cycles. Value of drift ratio was increasing until the pile failed [13]. The cycles of reversed lateral load are shown in Fig. 6. 


\section{The measurement of strain}

According to the schematic flexural behavior of spun pile due to lateral loading as shown in Fig. 7, due to reverse lateral load spun pile was deflected. While the lateral load was pushed (+), it caused tension stress on front PC bar and compression stress on rear side concrete of spun pile. While the lateral load was pulled (-), it will induce the tension on back PC bar and compression on front side concrete of spun pile.

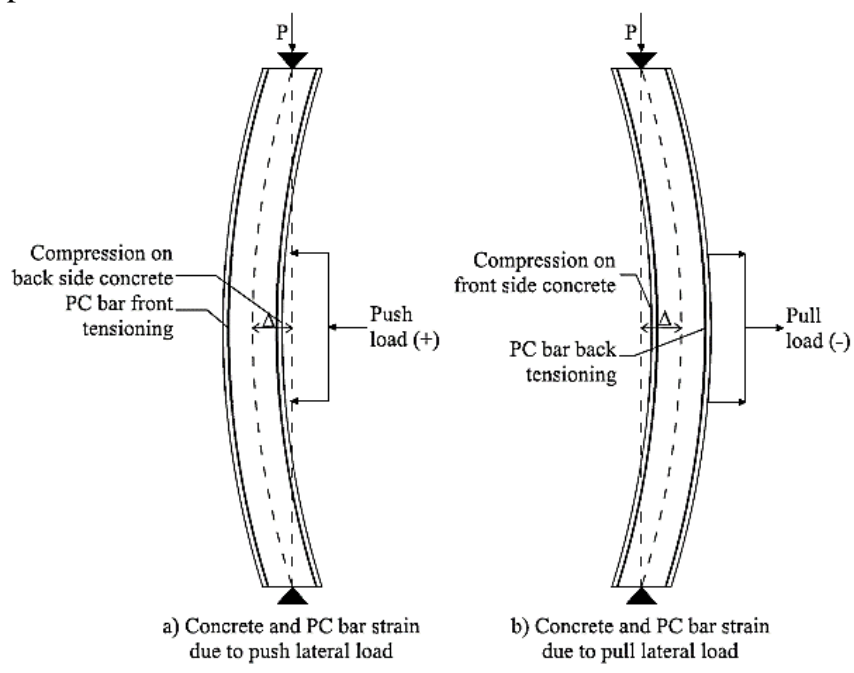

Fig. 7 The schematic flexural behavior of spun pile due to lateral loading
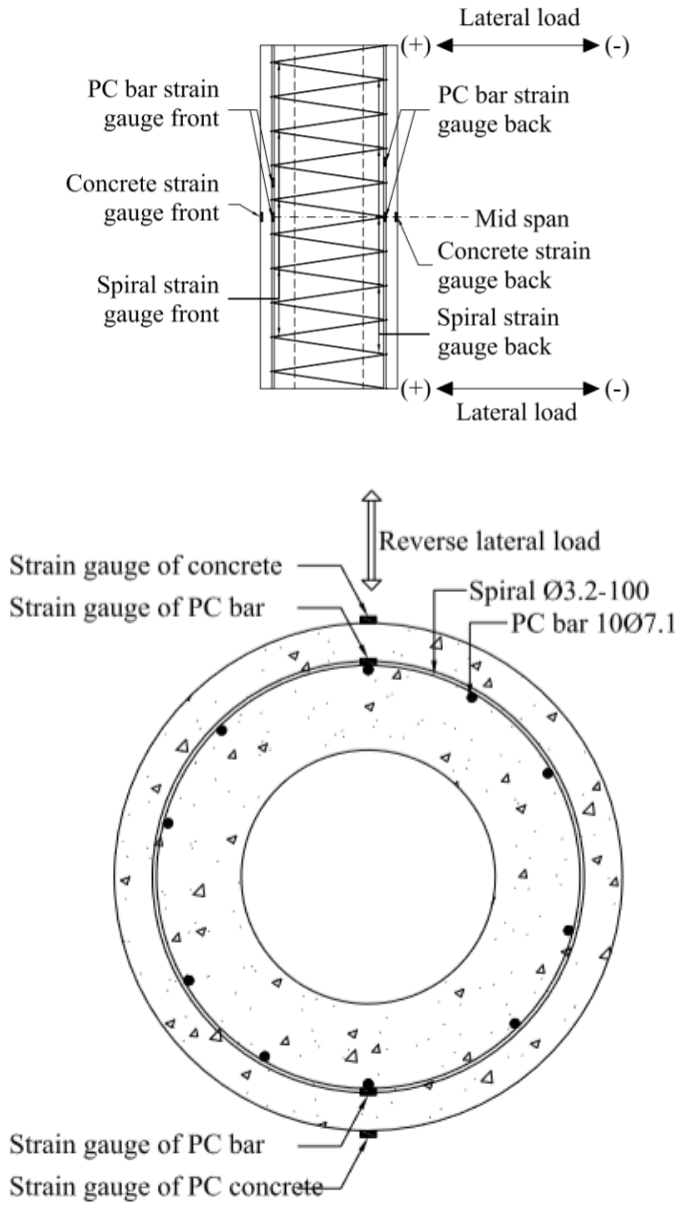

Fig. 8 The position of strain gauges of concrete and PC bar
In compression fiber concrete, the confinement mechanism occurred. In ultimate condition, the crushing of concrete was resisted by confining force of spiral reinforcement. The strains of spiral reinforcement were recorded using strain gauge mounted on the surface of the spiral wire. Strain gauges of spiral reinforcement were mounted in the front and the rear side in some locations and placed on the middle span $(\mathrm{x}=0), 200 \mathrm{~mm}$ and $400 \mathrm{~mm}$ above and below of middle span $(\mathrm{x}=+200, \mathrm{x}=+400)$ and below of middle span $(\mathrm{x}$ $=-200, x=-400)$.

The compression and tension strain of concrete and PC bar due to flexural loading was recorded using strain gauge. Fig. 8 showing the position of a strain gauge on concrete and PC bar. Both face of concrete in the same direction of lateral load. The recorded strain was ready by data logger instrument.

\section{RESULT AND DISCUSSION}

\section{A. Failure Mode of Specimens}

Irawan et al. [5] conducted a detailed analysis of the loaddisplacement relationship of tested spun piles. The hysteresis curve of the load-displacement due to reverse lateral loading is shown in Fig. 9. In this study displacement ductility, the ratio of ultimate displacement to yielding displacement was intensively analyzed. Specimen S-TB-1 withstand until maximum displacement ductility $\mu_{\Delta}=4.8$. The increasing of axial load on specimen S-TB-3 caused spun pile early collapsed at lower displacement ductility $\mu_{\Delta}=2.4$. The not very high of the ductility of hollow column, around three or four, is also obtained from previous research [8][14].
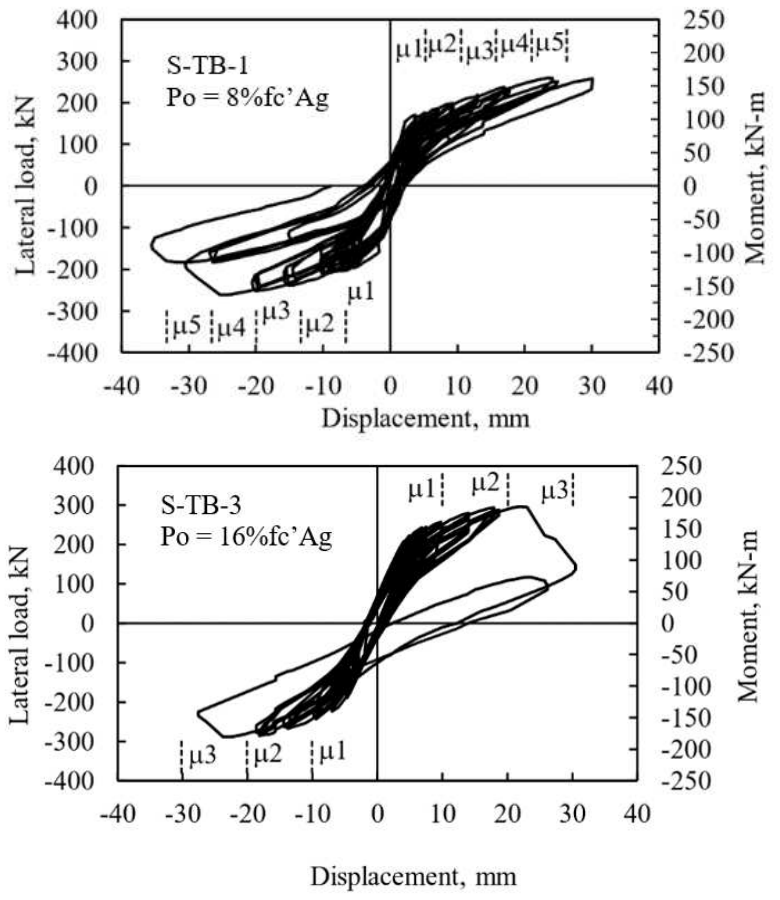

Fig. 9 Hysteresis load (moment) and displacement of the spun pile under cyclic loading [5]

The increasing of the axial load was increasing the peak moment capacity of the spun pile, especially at crack and 
yield stage. Nevertheless, the slightly decreasing of ultimate moment capacity was achieved [5].

As shown in Fig. 10 and Fig. 11, the failure patterns of both specimens were compared. The concrete crushing occurred in the front and the rear face of S-TB-1 specimen. The damage occurred at load pull. This failure mode corresponding to the load-displacement curve of S-TB-1 [5], see Fig. 9. At displacement ductility $\mu_{\Delta}=4.8$ the lateral load capacity was decreasing. Another scenario was apparent in specimen S-TB-3 where the explosion at high bending moment region was inevitable due to higher axial load level being applied to specimen S-TB-3 (see Fig. 11). After peak load, excessive reduction of flexural capacity rapidly occurred.

According to visual observation throughout the loading phase, the test specimens failed in less desirable brittle manner. In each of test specimen, it was evident that the failure due to outside wall concrete crushing occurred after the specimen achieved the peak capacity. After spalling of cover concrete, the buckling of PC bars was clearly observed. This type of failure was corresponding to the previous testing conducted by Budek and Priestly. The failure of hollow section prestressed pile was caused by the compression failure of the shell [8]. Inside face of concrete wall crushing also causes the failure of hollow columns or piles [14][15]. The decreasing of peak loads of hollow prestressed piles under lateral load was initiated by the concrete cover spalling. Due to the large axial load applied on pile caused spalling concrete cover and buckling of PC bar or longitudinal bar was early occurred [18].

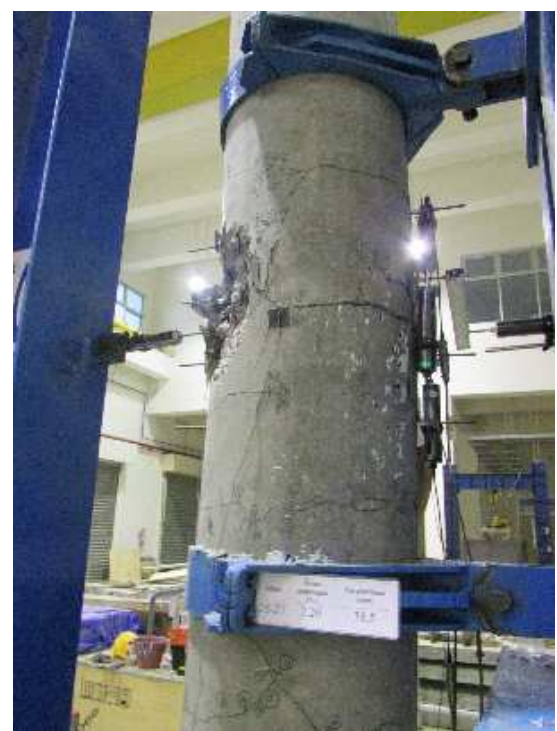

Fig. 10 The crushing on the front and the rear face of specimen S-TB-1

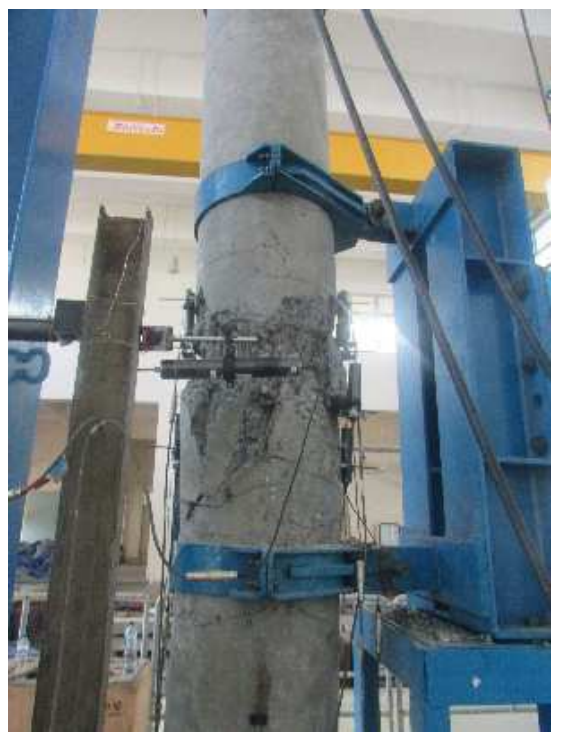

Fig. 11 Totally explosion damage of specimen S-TB-3

\section{B. The Strain of Concrete and PC Bar}

The recorded strain of concrete and PC bar as the behavior of the failure mechanism of the pile is presented in Fig. 12 and Error! Reference source not found.. Through the reading of strain gauges on concrete, it appeared from the Fig. 12 that the strain of concrete for S-TB-1 and S-TB-3 are $5,008 \mu \varepsilon$ and $4,252 \mu \varepsilon$, meaning that the strains have exceeded the limit of strain at crushing, i.e. $\varepsilon_{\mathrm{cu}} 3,000 \mu \varepsilon$ [17]. The crushing phenomenon occurred.
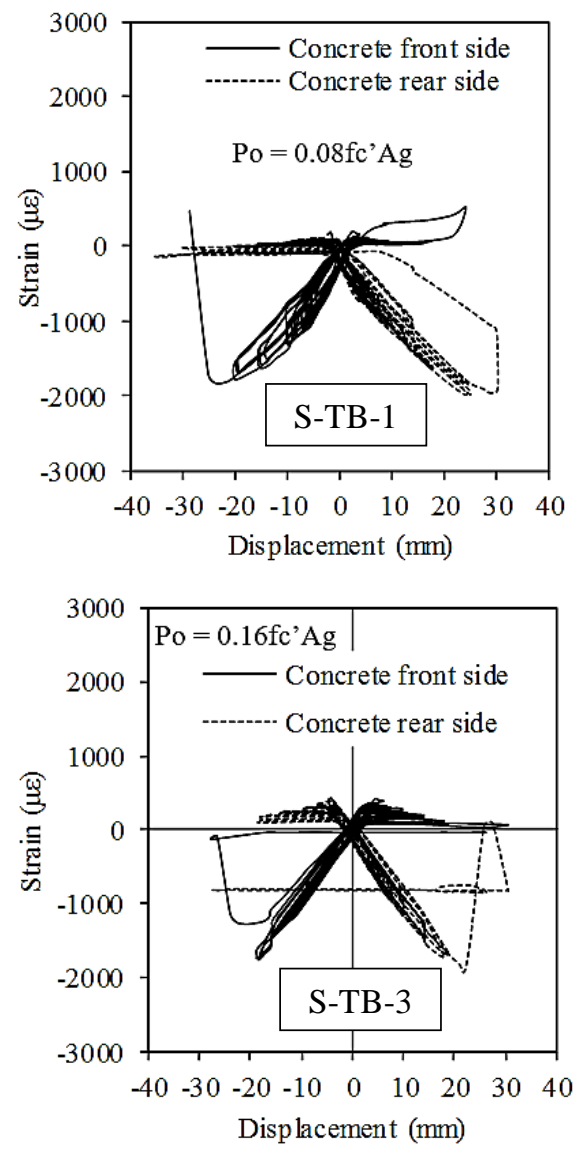

Fig. 12 The strain of concrete of S-TB-1 and S-TB-3 
The readings of strain gauges of PC bar are shown in Error! Reference source not found.. It can be seen, the corresponding tensile strains of $\mathrm{PC}$ bars at maximum load are 6,460 $\mu \varepsilon$ and 5,383 $\mu \varepsilon$ for specimen S-TB-1 and S-TB-3, respectively. However, due to initial prestressing of 5,000 $\mu \varepsilon$ caused tensile strain values of the specimens go up 11,460 $\mu \varepsilon$ and $10,383 \mu \varepsilon$. These strains are now known to be less than ultimate strain limit which is $22,529 \mu \varepsilon$. It implies that the failure is dominated only by concrete crushing. The concrete crushing caused the PC bar was buckling. This phenomenon was depicted by the suddenly decreasing of the compressive strain of PC bar.
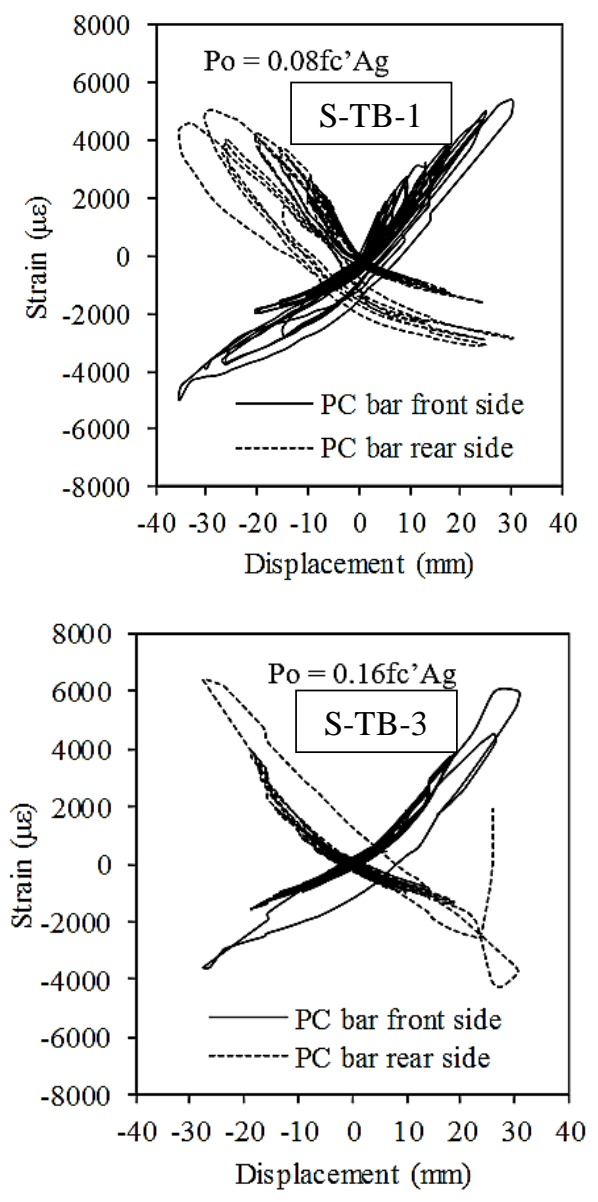

Fig. 13 The strain of PC bar of S-TB-1 and S-TB-3

\section{The Strain of Spiral Reinforcement Analysis}

The readings of strain at spiral steel from specimen S-TB-1 and S-TB-3 are shown in Error! Reference source not found.. Each figure represents the record of strain starting from initial loading condition until the specimens failed. Before concrete crushing, the average of tensile strains of spiral steel is $30 \mu \varepsilon$. When the load is at the peak point, the jump of tensile strain occurs with the value increased around $1,330 \mu \varepsilon$. This value is lower than yield strain of spiral steel which is 3,067 $\mu \varepsilon$ (see Fig. 4); hence, it is clear that transverse reinforcement has not been yielded. However, it is impeccable that some gauges have shown simultaneous event of concrete crushing at the same time when spiral steels are subjected to compression.

Effective confinement of concrete section occurred when transverse reinforcement was yield to resist the concrete crushing [16]. As the result of the phenomena captured from the experimental investigation, it can be said that the utilization of low amount of spiral reinforcement governs the tendency in which concrete in extreme compression fiber behaves as unconfined concrete. Considering this fact, good confinement of hollow column or pile is not then achieved which would also affect the ductile performance of pile. The small spacing of spiral reinforcement on hollow pile has no significant effect on the ductility capacity [8]. Without the presence of concrete core on the hollow pile, close spacing of spiral reinforcement is not crucial because a brittle failure occurred after concrete cover spalling [18]. The confining pressure of inside surface of the concrete wall in hollow columns from confining reinforcement is smaller than in solid columns [14]. The low lateral confining action is the characteristic of hollow concrete columns or piles [8][14].
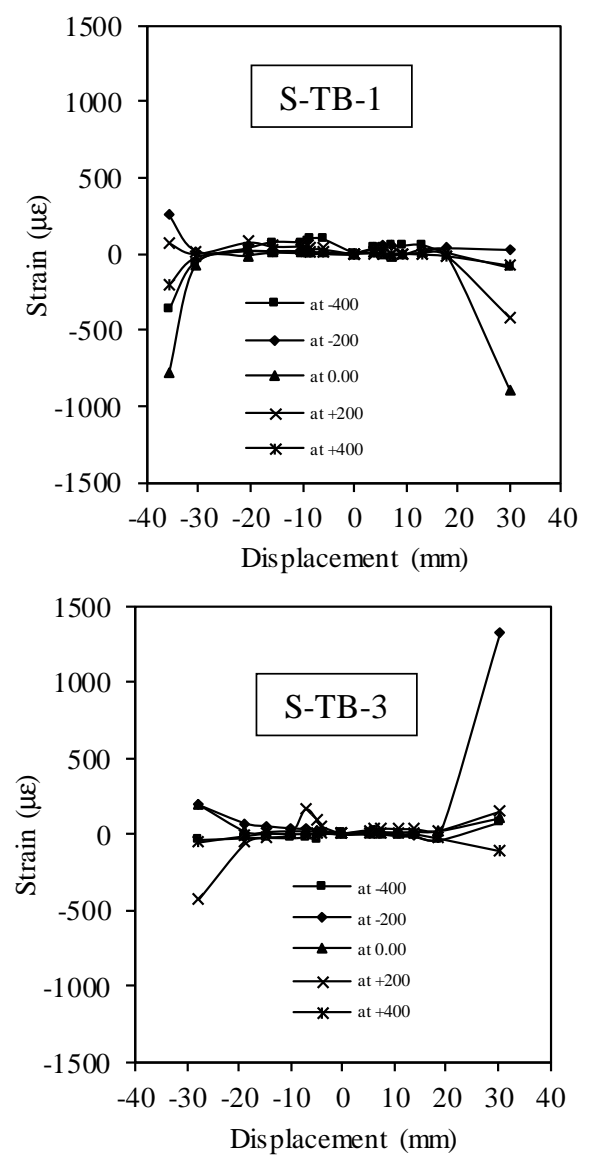

Fig. 14 The resume strain of spiral wire of specimens S-TB-1 and S-TB-3

\section{CONCLUSIONS}

Regarding the results of the experimental work as presented above, the following conclusions can be drawn: The ultimate strength of prestressed hollow pile spun pile, due to reverse flexure load combined with constant axial load is reached due to the crushing failure of concrete on compression fiber. Crushing of concrete at shell occurs at fiber compression strain of $\varepsilon_{\mathrm{c}} \approx 5000 \mu \varepsilon$. The recorded strain of spiral reinforcement shows that low amount of spiral reinforcement poorly contributes the confinement of spun pile's section. Spiral reinforcement does not resist the explosion of pile's concrete section at ultimate state due to compression. Its tensile strain does not achieve yield limit; 
moreover, spiral reinforcements are compressed coincided with the compression damage of concrete.

\section{NOMENCLATURE}

$\begin{array}{lll}\text { f } & \text { stress } & \mathrm{MPa} \\ \text { A } & \text { area } & \mathrm{mm}^{2} \\ \text { P } & \text { axial load } & \text { tons }\end{array}$

Greek letters

$\rho \quad$ ratio of reinforcement

$\varepsilon \quad$ strain

$\mu \quad$ ductility

$\begin{array}{ll}\text { Subscripts } \\ \mathrm{c} & \text { concrete } \\ \mathrm{t} & \text { transverse steel } \\ 0 & \text { initial } \\ \mathrm{g} & \text { gross } \\ \Delta & \text { displacement } \\ \mathrm{u} & \text { ultimate }\end{array}$

\section{ACKNOWLEDGMENT}

The authors would like to acknowledge: PT Wijaya Karya Beton, Tbk. for funding through research collaboration of ITS Surabaya, UNHAS Makassar and PT Wijaya Karya Beton, Tbk. The Ministry of Research, Technology and the Higher Education Republic of Indonesia for the Doctoral Scholarship for the first author.

\section{REFERENCES}

[1] R. Park and T. Paulay, Reinforced Concrete Structures, New York: John Wiley \& Sons, 1975.

[2] R. Park, and T. J. Falconer, "Ductility of Prestressed Concrete Piles Subjected to Simulated Seismic Loading", PCI Journal, pp. 112-144, September-October 1983.

[3] P. H. Joen, "Seismic Performance of Prestressed Concrete Piles and Pile-Pile Cap Connections", Doctorate Thesis, University of Canterbury, Christchurch, New Zealand, December 1987.

[4] A. M. Budek, G. Benzoni and M. J. N. Priestly, "Experimental Investigation of Ductility of In-Ground Hinges in Solid and Hollow Prestressed Piles", Division of Structural Engineering University of California, 1997.
[5] C. Irawan, I. G. P. Raka, R. Djamaluddin, P. Suprobo and Gambiro, "Ductility and Seismic Performance of Spun Pile under Constant Axial and Reverse Flexural Loading", in Proc. International Symposium on Concrete Technology, Makassar, 2017, p. 35.

[6] N. Takase, M. Ikegame, Tanamura S., A. Nishimura and M. Kondou, "Seismic Design of Pile Foundation", QR of RTRI., vol. 40 No.3, pp. 152-157, October 1999.

[7] N. M. Hawkins and S. K. Ghosh, "Proposed Revisions to 1997 NEHRP Recommended Provisions for Seismic Regulations for Precast Concrete Structure", PCI Journal, pp. 34-44, SeptemberOctober 2000

[8] A. M. Budek and M. J. N. Priestly, "Experimental Analysis of Flexural Hinging in Hollow Marine Prestressed Pile Shaft", Coastal Engineering Journal, vol. 47, No. 1, pp. 1-20, 2005.

[9] S. Ikeda, T. Tsubaki, and T. Yamaguchi, "Ductility improvement of prestressed concrete piles," Transactions of the Japan Concrete Institute, vol. 4, pp. 531-538, 1982.

[10] H. Muguruma, F. Watanabe, and M. Nishiyama, "Improving The flexural Ductility of Pretensioned High Strength Spun Concrete Piles by Lateral Confining of Concrete," in Proc. Pacific Conference on Earthquake Engineering, Wairakei, New Zealand, 1987, vol. 1, pp. 385-396.

[11] R. Tuladhar, H. Mutsuyoshi, T. Maki, and K. Daigo, "Lateral Loading Tests of Full Scaled Concrete Piles Embedded into the Ground", Bulletin of Engineering Faculty Saitama University, No. 38, pp. 74-80, 2005.

[12] A. M. Budek, M. J. N. Priestley, and G. Benzoni, "Inelastic Seismic Response of Bridge Drilled-Shaft RC Pile/Columns", Journal of Structural Engineering, 126(4) pp. 510-517, 2000.

[13] Acceptance Criteria for Moment Frames Based on Structural Testing and Commentary, ACI Committee 347.1, 2005.

[14] X. Liang, R. Beck, S. Sritharan, "Understanding the Confined Concrete Behavior on the Response of Hollow Bridge Columns", Iowa State University of Science and Technology, 2015.

[15] J. Hoshikuma, and M.J.N Priestly, "Flexural Behavior of Circular Hollow Columns with a Single Layer of Reinforcement under Seismic Loading", Department of Structural Engineering University of California, 2000.

[16] R. Park, M. J. N. Priestley, T. J. Falconer, and P. H. Joen, "Detailing of Prestressed Concrete Piles for Ductility", Bulletin of the New Zealand National Society for Earthquake Engineering, pp. 251-271, 1984.

[17] Building Code Requirements for Structural Concrete, ACI 318, 2014.

[18] M. Akiyama, S. Abe, N. Aoki, and M. Suzuki, "Flexural Test of Precast High-strength Reinforced Concrete Pile Prestressed with Unbonded Bars Arranged at the Center of the Cross-section", Engineering Structures 34, p. 259-270, 2012. 